\title{
Endovascular Treatment of Acute Stroke: Evolution and Selection of Techniques and Instruments Based on Thrombus Imaging
}

\author{
T. Liebig $\cdot$ J. Gralla $\cdot$ G. Schroth
}

Received: 31 March 2015 / Accepted: 8 June 2015 / Published online: 28 July 2015

(C) The Author(s) 2015. This article is published with open access at Springerlink.com

\begin{abstract}
Mechanical thrombectomy provides higher recanalization rates than intravenous or intra-arterial thrombolysis. Finally this has been shown to translate into improved clinical outcome in six multicentric randomized controlled trials. However, within cohorts the clinical outcomes may vary, depending on the endovascular techniques applied. Systems aiming mainly for thrombus fragmentation and lacking a protection against distal embolization have shown disappointing results when compared to recent stent-retriever studies or even to historical data on local arterial fibrinolysis. Procedure-related embolic events are usually graded as adverse events in interventional neuroradiology. In stroke, however, the clinical consequences of secondary emboli have so far mostly been neglected and attributed to progression of the stroke itself. We summarize the evolution of instruments and techniques for endovascular, image-guided, microneurosurgical recanalization in acute stroke, and discuss how to avoid procedure-related embolic complications.
\end{abstract}

Keywords Near-infrared spectroscopy $\cdot$ NIRS $\cdot$ Stent retriever $\cdot$ Stroke $\cdot$ Thrombus imaging

Prof. Dr. G. Schroth, MD $(\bowtie) \cdot J$. Gralla, MD, MSc

Institute for diagnostic and interventional Neuroradiology,

Inselspital - University Hospital,

3010 Bern, Switzerland

e-mail: Gerhard.schroth@insel.ch

T. Liebig, MD

Department of Neuroradiology, University Hospital of Cologne,

Cologne, Germany

\section{Introduction}

One of the most important predictors of clinical outcome after acute ischemic stroke is recanalization of the primary occlusion with subsequent reperfusion of the brain. The success rate is also influenced by the initial severity of the ischemic lesion, the pre-existing collaterals, the age of the patient, and the time between onset of symptoms and recanalization $[1,2]$. The initial severity of stroke, rated by the National Institutes of Health Stroke Scale (NIHSS) score, is normally higher in big vessel occlusions (internal carotid-, middle cerebral-, and basilar arteries) [3]. At the same time, the rate of timely recanalization by intravenous thrombolysis is low in big vessel occlusions especially if the thrombus length exceeds $8 \mathrm{~mm}$ [4]. Conversely, mechanical thrombectomy can achieve recanalization rates up to $90 \%$, independent of the location and length of the thrombus [5], even in T-/L- or tandem occlusions of the internal carotid artery and its branches $[6,7]$.

In accordance with the specifications of this anniversary issue, this article brings into focus the evolution of instruments and current techniques for revascularization of big vessel occlusions in acute stroke. Stroke registries and trials are the topic of another article in this issue, which will appreciate also the recent groundbreaking ESCAPE; EXTEND, REVASCAT, THRACE and SWIFT-PRIME clinical trials, following the pioneering MRCLEAN study.

\section{Intra-arterial Pharmacological Thrombolysis}

With this technique that is of historical relevance because it was the first to be applied by neuroradiologists in Germany in the early 1980 s, a microcatheter is navigated via a microwire to the occlusion site and used to inject thrombolytic drugs 
proximal to (PROlyse in Acute Cerebral Thrombembolism; PROACT) or directly into the thrombus (Middle cerebral artery Embolism Local fibrinolytic intervention Trial; MELT). Recanalization rates of $66 \%$ [8], 74\% [9], or even higher [10] were achieved, with subsequent high rates of good clinical outcome: $41 \%$ [8] and 49\% [9]. Local intraarterial thrombolysis therefore provides an inexpensive and relatively low-risk alternative when endovascular access is difficult, the site of occlusion is distal, or the calibers of the carotid or vertebral arteries are small. However, this treatment has been vastly replaced by techniques aiming at the mechanical retrieval of clot.

\section{Mechanical Treatment Approaches}

Endovascular mechanical treatment approaches can be divided into five major groups according to their mechanism of action:

- Thrombus disruption,

- Proximal thrombectomy, thrombaspiration

- Distal thrombectomy

- Stent recanalization

- Retrievable stents (stent retriever)

\section{Thrombus Disruption}

The goal of this technique is to increase the contact surface and penetration of the thrombolytic drug into the clot. Probing and fragmenting the thrombus with the microwire was the most frequently applied technique. Because the microwire and the microcatheter never penetrate the thrombus itself, but pass the site of occlusion between the vessel wall and the thrombus [11], the risk of local spasms, dissections, and iatrogenic distal emboli is high. Nevertheless, when the technique was used as an adjunct to intra-arterial thrombolysis, successful recanalization of M1 occlusions was achieved in $79 \%$ of patients [10]. Another method of mechanical clot disruption is the use of percutaneous transluminal balloon angioplasty (PTA). Due to the risk of procedural complications and distal vessel occlusion due to emboli, this technique has not been accepted as a first-line treatment. More elaborated thrombus disruption devices apply ultrasound or laser technology (EKOS, Bothell, USA; EPAR, Endovasix, Belmont, USA), however the application was limited due to the restricted availability, costs, and complications such as iatrogenic distal emboli, intracranial hemorrhages, and dissections caused by the rigid catheters.
Proximal Thrombectomy and Thrombaspiration

Manual suction thrombectomy is performed by advancing an aspiration catheter (usually 5-5.5-F) to the proximal surface of the thrombus. Manual aspiration is applied using a syringe. The aspiration catheter is then retrieved under constant negative pressure. Aspiration catheters must be flexible enough to pass the tortuosity of the cranial vessels, such as the carotid siphon, braided enough not to collapse during aspiration, and big enough to catch and hold the thrombus.

Following the introduction and European Conformity (CE) certification of a dedicated 5-F aspiration catheter (VASCO-ASP, Balt), this approach was used in a multimodal treatment approach for proximal occlusions of vessels such as the distal cervical internal carotid artery, the carotid terminus, or the basilar artery (Fig. 1). The drawback of this technique is the possible fragmentation of thrombotic material [12-13] due to elongation of the thrombus during aspiration, which remains a problem even since the introduction of more flexible distal access catheters with larger bore. Thrombotic fragments obstruct the aspiration catheter and prohibit further aspiration, which requires retrieval and repositioning of the system.

The Penumbra system (Penumbra, Almeda, USA) is a modification of the manual proximal aspiration technique and consists of a dedicated reperfusion catheter connected to a pumping system that applies continuous suction. A microwire with an olive-shaped tip, the separator, is used to clean the tip of the reperfusion catheter of clot fragments in order to avoid obstruction. Despite the relatively high recanalization rate, poor clinical outcomes prompted discussion of the impact of recanalization using mechanical thrombectomy. Procedural-related iatrogenic emboli are one reason for the disappointing clinical outcome of this technique [14].

Both of these catheter systems may be used in combination with distal devices such as stent retrievers of combine the effects or to facilitate reaccess in case of futile thrombectomy.

\section{Distal Thrombectomy}

Compared to proximal thrombectomy approaches, distal thrombectomy is technically more challenging because the occlusion site has to be passed with a microcatheter in order to deliver the device to the distal side of the thrombus. Several distal thrombectomy devices have been introduced into clinical practice (e.g., Catch, BALT, Montmorency, France; Phenox pCR/CRC/Bonnet, Phenox GmbH, Bochum, Germany; Merci device, Concentric Medical, Mountain View, USA).

In the Multi-MERCI trial [15], successful recanalization was achieved in $57.3 \%$ of patients using the Merci retriever 

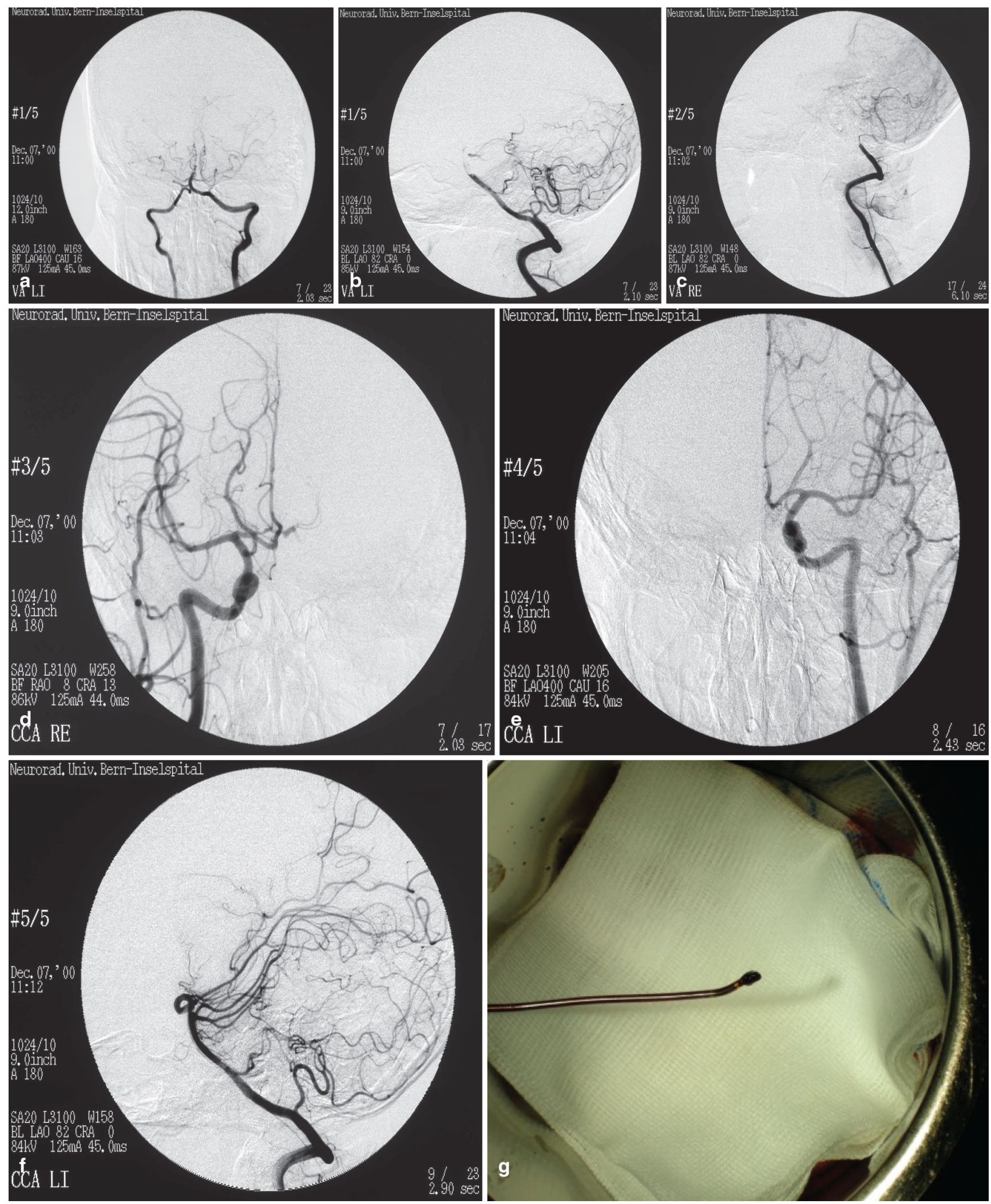

Fig. 1 Thrombaspiration in an 18-year old patient with basilar occlusion after cardiac OP. Start of the angio at 10:50, Dec 7th, 2000. Digital subtraction angiography (DSA) of the left vertebral artery at 11:00 confirmed basilar artery occlusion in frontal (a) and lateral (b) right common carotid artery at 11:03 (d). DSA of the left carotid artery at 11:04 (e). Control DSA of the left VA, 11:12, following aspiration of the thrombus confirmed TICI-3 recanalization (f). Thrombus fixed and removed at the top of the $5-\mathrm{F}$ aspiration catheter $(\mathbf{g})$ 
alone and in $69.5 \%$ using additional recanalization modalities. However, favorable clinical outcome was achieved in only $36 \%$. A high rate of thrombus fragmentation and iatrogenic emboli reported in experiments using Merci and other distal access devices [16] may serve as explanation. Nevertheless, the MERCI and Multi-MERCI trials promoted the introduction of the Merci device into widespread use for clinical studies, especially in the so-called unhappy triad [17-19].

\section{Stent Recanalization}

In comparison to thrombectomy devices, stenting allows fast and effective recanalization without repetitive passing of the occlusion site and retrieval attempts. However, this straight-forward concept has some disadvantages during treatment of acute stroke. Permanent stent placement requires double platelet antiaggregation in order to prevent in-stent thrombosis and reocclusion, thrombus compression may lead to permanent side branch or perforator occlusion, and the rate of in-stent restenosis is high. However, stenting is clearly valuable in selective cases of rescue therapy when other recanalization methods have failed, and in the acute phase of stroke treatment in case of an underlying intracranial stenosis (Fig. 2). Therefore, stenting is more frequently used in vertebrobasilar stroke in order to reduce the risk of reocclusion across a stenosis.

Self-expandable stents are preferentially used over balloon-mounted stents and recanalization rates between $79 \%$ and $92 \%$ with moderate clinical outcome in $33-50 \%$ [20] can be achieved.

\section{Stent Retriever}

The application of stent retrievers is comparable to that of intracranial stents. Initially, the occlusion site is passed with a microcatheter. Knowledge of the length and extension of the thrombus based on thrombus imaging, either using high resolution $\mathrm{CT}$ with thin slices, or T2* and SWI MR- techniques, is helpful $[4,5]$ to unsheathe the device over the whole length of the thrombus. Following slow injection of $1-2 \mathrm{ml}$ contrast to confirm the position of the microcatheter in a sufficiently large artery distal to the thrombus, the stent retriever is deployed by retrieving the microcatheter
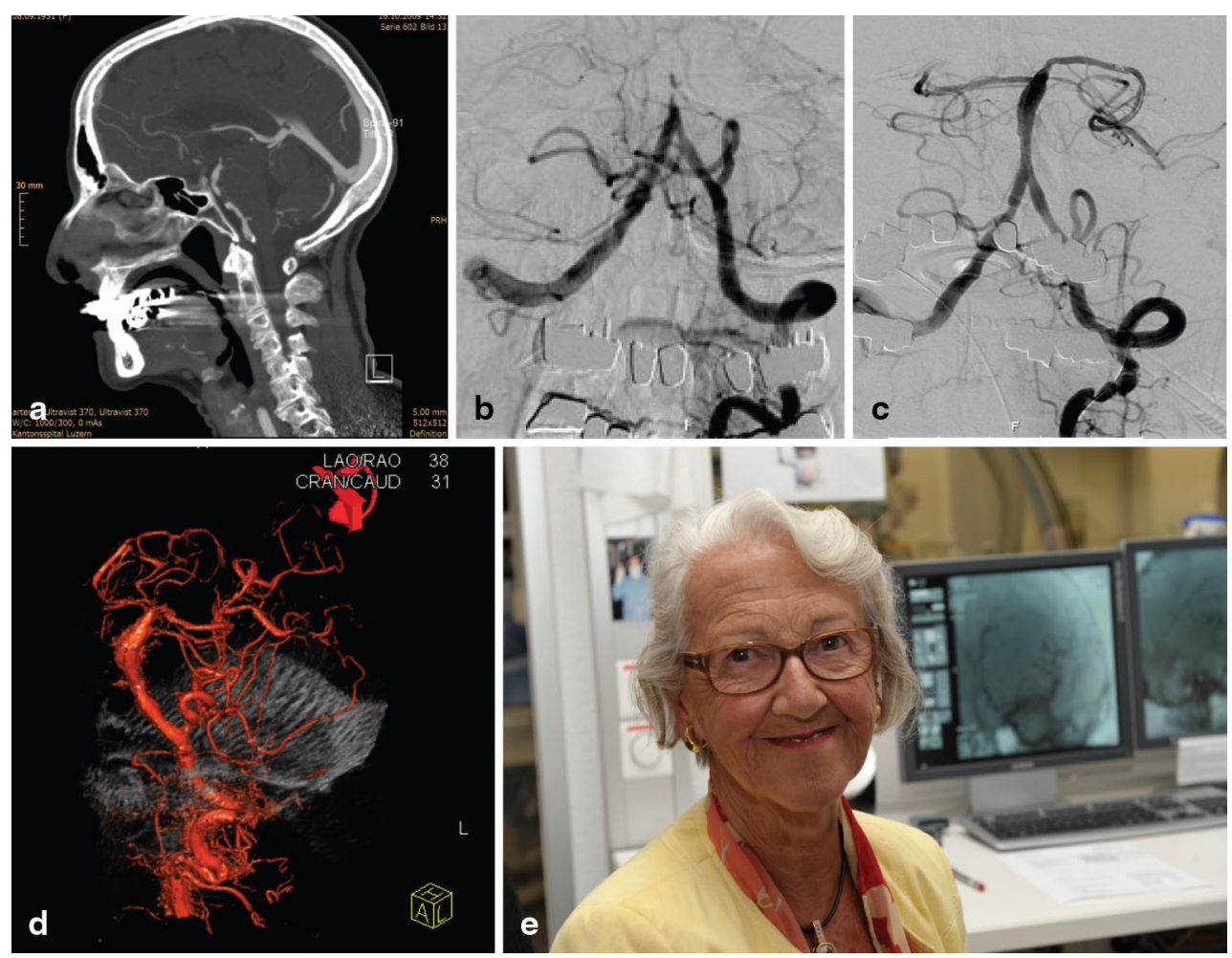

Fig. 2 Images from a 78-year-old female with progressive stroke. Computed tomography (CT) angiography from an external stroke unit showed mid-basilar occlusion (a), after which the patient was transferred via helicopter to our stroke center. Digital subtraction angiography (DSA) of the left vertebral artery confirmed mid-basilar occlusion (b). Recanalization was achieved with percutaneous transluminal balloon angioplasty (PTA) and implementation of a wingspan stent (c). At the 3-month follow-up flat panel 3-D rotation angiography with intravenous (i.v.) contrast showed normal flow in the basilar artery (d). After recovery to mRankin 0 , the now 79 -year-old patient agreed to inclusion of her photo (e), though she complained: "The helicopter flight was very interesting - however it was a little bit too cold - and I could not vocalize that and I was also unable to move and to pull the woolen blanket over me." Retrospectively we became aware, that the patient had a locked-in syndrome, which we - fortunately — did not recognize, because it might have been a criteria for excluding treatment 
and unsheathing the device covering the entire thrombus. The radial force of the stent retriever potentially generates a channel by compressing the thrombus and thereby partially restores blood flow to the distal territory in most cases, creating a channel for a temporary bypass. Recently, a new generation of stent retrievers has been introduced, addressing this potential benefit by a double stent-lumen design [21]. The immediate bypass effect has been confirmed using nearinfrared spectroscopy (NIRS) in patients with acute stroke (Fig. 3) after having tested this technique in other neurovascular procedures [22]. The stent retriever is typically left in place for an embedding time of 2-5 min, especially when the immediate bypass works effectively, allowing engagement of the thrombus within the stent struts.

To avoid iatrogenic emboli during mobilization and retraction of the thrombus, proximal and distal protection techniques have been developed that can be applied in combination.

During mobilization and retraction of the stent retriever, proximal balloon occlusion and flow reversal by additional aspiration at the guide catheter are recommended. The introduction of this proximal protection was followed by a significant improvement in the rate of recanalization as well as the clinical outcome [23-25], compared to the use of stent retrievers without mandatory use of protection devices [2628]. We presume, however, that the force of aspiration can only be transmitted to the intracranial arteries when the tip of the 8- or 9-F balloon-mounted guiding catheter is navigated close to the petrous part of the ICA, because from this point the artery is embedded in the bone and cannot collapse as easily during aspiration. Thrombaspiration with the top of an 8-F guiding catheter at the skull base and proximal flow arrest enables aspiration of clot material extending to the carotid $\mathrm{T}$ and beyond [29].

The distal protection technique consists of a triaxial catheter access: an intermediate, large bore (at least 5-F) aspiration catheter is placed through the 8- or 9-F balloonmounted guiding catheter just in front of the occlusion and the microcatheter is advanced over the microwire through the site of occlusion. The intermediate catheter can be placed in the first step or as a second step [2].

We prefer to deliver the stent retriever during the first step to supply oxygen as quickly as possible to brain tissue distal to the site of occlusion (Fig. 3). The next step is the removal of the microcatheter, which is sometimes challenging because stent retrievers with long exchange wires are not available. Injection of saline into the microcatheter with high pressure (using a $3 \mathrm{~mm}$ syringe) is a helpful technical trick to remove the microcatheter. The intermediate aspiration catheter is than loaded and navigated over the 0.014 inch wire of the stent retriever in front of the site of occlusion.
By adding the traction force of the stent retriever, which is applied over the whole length of the thrombus, and the suction force of the intermediate aspiration catheter, in addition to the negative pressure of the balloon-mounted guiding catheter, the rate of recanalization can be increased, iatrogenic emboli diminished and the clinical outcome improved.

\section{Discussion}

Following the pioneering work of Mori, Zeumer, and Theron, other experts in the field of interventional neuroradiology have evaluated the methods used in the PROACT and MELT clinical trials, and reported rates of recanalization of about $70 \%$ with good clinical outcome in more than $40 \%[8,9]$. We confirmed and improved these results, using this inexpensive and low-risk technique since 1992 in combination with aspiration $[10,29]$ after $\mathrm{CE}$ certification of a dedicated 5-F aspiration catheter (VascoAsp, BALT). We changed to stent retriever technology after in vitro and preclinical experiments confirmed that the occluding thrombus could be removed en bloc independently of its length [5].

Stent retriever technology is a definite step forward but albeit its methodologic simplicity not a "no brainer". Clinical outcome in studies using stent retriever thrombectomy without protection against iatrogenic emboli [27-29] were not convincing despite relatively high rates of revascularization. Likewise, studies using mainly or exclusively thrombus fragmenting techniques and instruments have shown disappointing results $[14,15,17-19]$.

Comparable to coiling of an aneurysm or embolization of an arteriovenous malformation (AVM), recanalization in acute stroke is an image-guided endovascular microneurosurgical operation, navigated by a biplane or 3D roadmap with a spatial resolution of 150 microns and a time resolution below $100 \mathrm{~ms}$. For treatment of stroke, however, we must also navigate our microinstruments distally from the site of occlusion blindly, without a precise picture of our roadmap. New developments in the field of diagnostic neuroradiology will enable us to match the virtual anatomy of the vessels distal to the site of occlusion. This will be performed in real time with biplane or 3-D roadmaps in the neuroangio-suite, using the late phases of CTA, MRA, or flat panel rotation angiography. In combination with thrombus imaging, we can guide our microinstruments safely and precisely beyond the site of occlusion, selectively in the branches of the MCA where the thrombus extends and that supply central regions of the hemisphere.

For planning the endovascular procedure, we consider it necessary to know the thrombus extent as well as each individual patient's angioarchitecture from the aortic arch up to the distal branches of the large intracranial arteries. In 


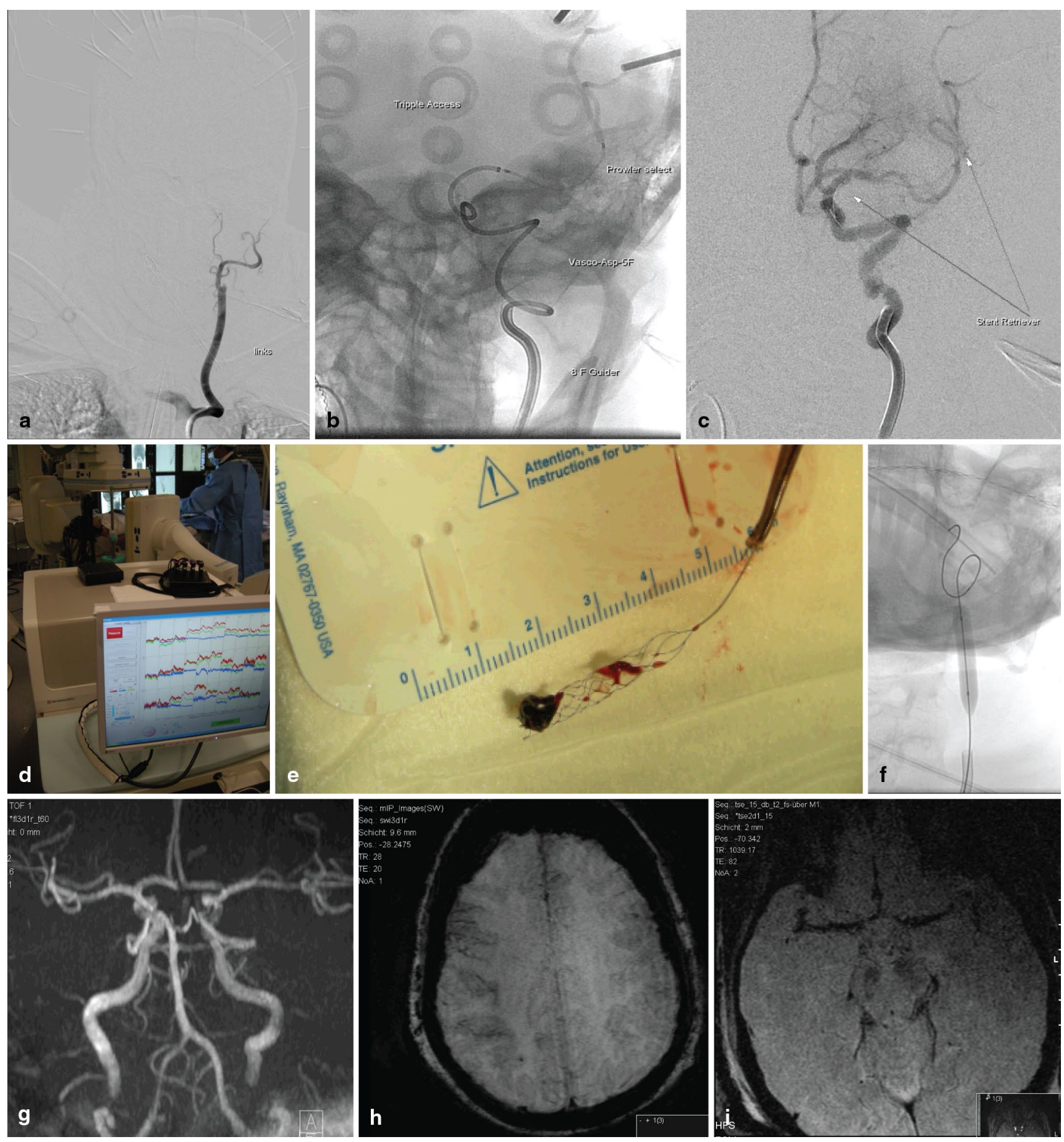

Fig. 3 A 64-year-old female with acute tandem occlusion and a NIHSS of 19 (National Institutes of Health Stroke Scale). Digital subtraction angiography (DSA) of the left common carotid artery confirms internal carotid artery (ICA) occlusion (a). Dottering of the ICA occlusion with a 8-F catheter and passage of the thrombus in the middle cerebral artery (MCA) with the microcatheter via a 5-F distal access catheter (b). The probes of the near-infrared spectroscopy (NIRS) are well seen; they have been mounted in 6 min during local anesthesia without time delay for the treatment. Following deployment of the stent retriever, which created a capillary lumen in the left MCA (c), NIRS recordings (d) confirmed an immediate and dramatic increase of oxy-hemoglobin (red lines) and total cortical blood (green lines); desoxyhemoglobin (blue lines) remained stable or decreased, which may reflect the core and penumbra of the infarct. The thrombus extracted from the MCA by simultaneous retrieval of the stent and aspiration through the distal aspiration catheter (e). Percutaneous transluminal balloon angioplasty (PTA) of the ICA occlusion (f) resulted in stable flow, which was closely monitored by bedside Doppler-sonography. Two days after MCA-thrombectomy and ICA-PTA, 3T MRI (Magnetic resonance imaging) quality control confirmed, that ICA and MCA remained open (g: time of flight magnetic resonance angiography (TOF-MRA), showed absence of iatrogenic distal emboli (h: whole brain susceptibility weighted imaging (SWI)) and confirmed intact vessel walls (i: dark blood vessel wall). Three month later, the mRankin was 0 and the patient's condition has remained stable for over 2 years 
daily practice, thrombus imaging guides us in the selection of the treatment approach. In patients with short thrombi measuring less than $8 \mathrm{~mm}$ in length, it may be warranted to start with intravenous thrombolysis and continue with endovascular therapy as a second step [2], however without a waiting period or delay to wait for clinical improvement but to proceed to endovascular treatment immediately. Based on modern thrombus imaging $[4,5]$ of the length and extension of the occlusion of the cerebral artery, the stent retriever can be deployed over the whole length of the thrombus in order not to shear off distal thrombus parts during mobilization and retraction of the thrombus.

The risk of embolic complications is of particular concern in mechanical thrombectomy, as emboli can impair collateral blood supply to the affected territory, accelerate penumbral tissue loss, and cause additional ischemic lesions. This is in accordance with a recent study demonstrating that the presence of multiple thrombi before initiation of thrombolytic therapy predicted worse outcome [30].

Open Access This article is distributed under the terms of the Creative Commons Attribution License which permits any use, distribution, and reproduction in any medium, provided the original author(s) and the source are credited.

\section{References}

1. Dorn F, Stehle S, Lockau H, Zimmer C, Liebig T. Endovascular treatment of acute intracerebral artery occlusions with the solitaire stent: single-centre experience with 108 recanalization procedures. Cerebrovasc Dis. 2012;34:70-7.

2. Gratz PP, Jung S, Schroth G, Gralla J, Mordasini P, Hsieh K, Heldner MR, Mattle HP, Mono M-L, Fischer U, Arnold M, Zubler C. Outcome of standard and high-risk patients with acute anterior circulation stroke after stent retriever thrombectomy. Stroke. 2014;45:152-8.

3. Fischer U, Arnold M, Nedeltchev K, Brekenfeld C, Ballinari P, Remonda L, Schroth G, Mattle HP. NIHSS score and arteriographic findings in acute ischemic stroke. Stroke. 2005;36:2121-5.

4. Riedel CH, Zimmermann P, Jensen-Kondering U, Stingele R, Deuschl G, Jansen O. The importance of size: successful recanalization by intravenous thrombolysis in acute anterior stroke depends on thrombus length. Stroke. 2011;42:1775-7.

5. Weisstanner C, Gratz PP, Schroth G, Verma RK, Köchl A, Jung S, Arnold M, Gralla J, Zubler C, Hsieh K, Mordasini P, El-Koussy M. Thrombus imaging in acute stroke: correlation of thrombus length on susceptibility-weighted imaging with endovascular reperfusion success. Eur Radiol. 2014;24:1735-41.

6. Lockau H, Liebig T, Henning T, Neuschmelting V, Stetefeld H, Kabbasch C, Dorn F. Mechanical thrombectomy in tandem occlusion: procedural considerations and clinical results. Neuroradiology. 2014.

7. Fischer U, Mono ML, Schroth G, Jung S, Mordasini P, El-Koussy M, Weck A, Brekenfeld C, Findling O, Galimanis A, Heldner MR, Arnold M, Mattle HP, Gralla J. Endovascular therapy in 201 patients with acute symptomatic occlusion of the internal carotid artery. Eur J Neurol. 2013;20:1017-24.
8. Furlan A, Higashida R, Wechsler L, Gent M, Rowley H, Kase C, Pessin M, Ahuja A, Callahan F, Clark WM, Silver F, Rivera F. Intra-arterial prourokinase for acute ischemic stroke. The PROACT II study: a randomized controlled trial. Prolyse in Acute Cerebral Thromboembolism. JAMA. 1999;282:2003-11.

9. Ogawa A, Mori E, Minematsu K, Taki W, Takahashi A, Nemoto S, Miyamoto S, Sasaki M, Inoue T. MELT Japan Study Group. Randomized trial of intraarterial infusion of urokinase within $6 \mathrm{~h}$ of middle cerebral artery stroke: the middle cerebral artery embolism local fibrinolytic intervention trial (MELT) Japan. Stroke. 2007;38:2633-9.

10. Arnold M, Schroth G, Nedeltchev K, Loher T, Remonda L, Stepper F, Sturzenegger M, Mattle HP. Intra-arterial thrombolysis in 100 patients with acute stroke due to middle cerebral artery occlusion. Stroke. 2002;33:1828-33.

11. Mordasini P, Brekenfeld C, Fischer U, Arnold M, El-Koussy M, Schroth G, Mattle HP, Gralla J. Passing the thrombus in endovascular treatment of acute ischemic stroke: do we penetrate the thrombus? Neuroradiol J. 2012;25:243-50.

12. Gralla J, Schroth G, Remonda L, Fleischmann A, Fandino J, Slotboom J, Brekenfeld C. A dedicated animal model for mechanical thrombectomy in acute stroke. AJNR Am J Neuroradiol. 2006;27:1357-61.

13. Gralla J, Schroth G, Remonda L, Nedeltchev K, Slotboom J, Brekenfeld C. Mechanical thrombectomy for acute ischemic stroke: thrombus-device interaction, efficiency, and complications in vivo. Stroke. 2006;37:3019-24.

14. Penumbra Pivotal Stroke Trial Investigators. The penumbra pivotal stroke trial: safety and effectiveness of a new generation of mechanical devices for clot removal in intracranial large vessel occlusive disease. Stroke. 2009;40:2761-8.

15. Smith WS, Sung G, Saver J, Budzik R, Duckwiler G, Liebeskind DS, Lutsep HL, Rymer MM, Higashida RT, Starkman S, Gobin YP; Multi MERCI Investigators, Frei D, Grobelny T, Hellinger F, Huddle D, Kidwell C, Koroshetz W, Marks M, Nesbit G, Silverman IE. Mechanical thrombectomy for acute ischemic stroke: final results of the Multi MERCI trial. Stroke. 2008;39:1205-12.

16. Brekenfeld C, Schroth G, El-Koussy M, Nedeltchev K, Reinert M, Slotboom J, Gralla. Mechanical thromboembolectomy for acute ischemic stroke: comparison of the catch thrombectomy device and the Merci Retriever in vivo. Stroke. 2008;39:1213-9.

17. Broderick JP, Palesch YY, Demchuk AM, Yeatts SD, Khatri P, Hill MD, Jauch EC, Jovin TG, Yan B, Silver FL, von Kummer R, Molina CA, Demaerschalk BM, Budzik R, Clark WM, Zaidat OO, Malisch TW, Goyal M, Schonewille WJ, Mazighi M, Engelter ST, Anderson C, Spilker J, Carrozzella J, Ryckborst KJ, Janis LS, Martin RH, Foster LD, Tomsick TA; Interventional Management of Stroke (IMS) III Investigators. Endovascular therapy after intravenous t-PA versus t-PA alone for stroke. N Engl J Med. 2013;368:893-903.

18. Ciccone A, Valvassori L, Investigators SE. Endovascular treatment for acute ischemic stroke. N Engl J Med. 2013;368:2433-4.

19. Kidwell CS, Jahan R, Gornbein J, Alger JR, Nenov V, Ajani Z, Feng L. A trial of imaging selection and endovascular treatment for ischemic stroke. N Engl J Med. 2013;368:914-23.

20. Brekenfeld C, Schroth G, Mattle HP, Do DD, Remonda L, Mordasini P, Arnold M, Nedeltchev K, Meier N, Gralla J. Stent placement in acute cerebral artery occlusion: use of a self-expandable intracranial stent for acute stroke treatment. Stroke. 2009;40:847-52.

21. Kabbasch C, Mpotsaris A, Liebig T, Söderman M, Holtmannspötter M, Cronqvist M, Thornton J, Mendes Pereira V, Andersson T. First-In-Man Procedural Experience with the Novel EmboTrap ${ }^{\circledR}$ Revascularization Device for the Treatment of Ischemic Stroke-A European Multicenter Series. Clin Neuroradiol. 2014. Nov 1. 
22. Rummel C, Zubler C, Schroth G, Gralla J, Hsieh K, Abela E, Hauf M, Meier N, Verma RK, Andres RH, Nirkko AC, Wiest R. Monitoring cerebral oxygenation during balloon occlusion with multichannel NIRS. J Cereb Blood Flow Metab. 2014;34:347-56.

23. Campbell BC, Mitchell PJ, Kleinig TJ, Dewey HM, Churilov L, Yassi N, Yan B, Dowling RJ, Parsons MW, Oxley TJ, Wu TY, Brooks M, Simpson MA, Miteff F, Levi CR, Krause M, Harrington TJ, Faulder KC, Steinfort BS, Priglinger M, Ang T, Scroop R, Barber PA, McGuinness B, Wijeratne T, Phan TG, Chong W, Chandra RV, Bladin CF, Badve M, Rice H, de Villiers L, Ma H, Desmond PM, Donnan GA, Davis SM; EXTEND-IA Investigators. Endovascular therapy for ischemic stroke with perfusionimaging selection. N Engl J Med. 2015;372:1009-18.

24. Goyal M, Demchuk AM, Menon BK, Eesa M, Rempel JL, Thornton J, Roy D, Jovin TG, Willinsky RA, Sapkota BL, Dowlatshahi D, Frei DF, Kamal NR, Montanera WJ, Poppe AY, Ryckborst KJ, Silver FL, Shuaib A, Tampieri D, Williams D, Bang OY, Baxter BW, Burns PA, Choe H, Heo JH, Holmstedt CA, Jankowitz B, Kelly M, Linares G, Mandzia JL, Shankar J, Sohn SI, Swartz RH, Barber PA, Coutts SB, Smith EE, Morrish WF, Weill A, Subramaniam S, Mitha AP, Wong JH, Lowerison MW, Sajobi TT, Hill MD; ESCAPE Trial Investigators. Randomized assessment of rapid endovascular treatment of ischemic stroke. N Engl J Med. 2015;372:1019-30.

25. Pereira VM, Gralla J, Davalos A, Bonafé A, Castaño C, Chapot R, Liebeskind DS, Nogueira RG, Arnold M, Sztajzel R, Liebig T, Goyal M, Besselmann M, Moreno A, Schroth G. Prospective, multicenter, single-arm study of mechanical thrombectomy using solitaire flow restoration in acute ischemic stroke. Stroke. 2013;44:2802-7.

26. Saver JL, Jahan R, Levy EI, Jovin TG, Baxter B, Nogueira R, Clark W, Budzik R, Zaidat OO; SWIFT Trialists. SOLITAIRE ${ }^{\mathrm{TM}}$ with the intention for thrombectomy (SWIFT) trial: design of a randomized, controlled, multicenter study comparing the SOLITAIRE $^{\text {TM }}$ Flow Restoration device and the MERCI Retriever in acute ischaemic stroke. Int J Stroke. 2014;9:658-68.
27. Nogueira RG, Lutsep HL, Gupta R, Jovin TG, Albers GW, Walker GA, Liebeskind DS, Smith WS; TREVO 2 Trialists. Trevo versus Merci retrievers for thrombectomy revascularisation of large vessel occlusions in acute ischaemic stroke (TREVO 2): a randomised trial. Lancet. 2012;380:1231-40.

28. Berkhemer OA, Fransen PS, Beumer D, van den Berg LA, Lingsma HF, Yoo AJ, Schonewille WJ, Vos JA, Nederkoorn PJ, Wermer MJ, van Walderveen MA, Staals J, Hofmeijer J, van Oostayen JA, Lycklama à Nijeholt GJ, Boiten J, Brouwer PA, Emmer BJ, de Bruijn SF, van Dijk LC, Kappelle LJ, Lo RH, van Dijk EJ, de Vries J, de Kort PL, van Rooij WJ, van den Berg JS, van Hasselt BA, Aerden LA, Dallinga RJ, Visser MC, Bot JC, Vroomen PC, Eshghi O, Schreuder TH, Heijboer RJ, Keizer K, Tielbeek AV, den Hertog HM, Gerrits DG, van den Berg-Vos RM, Karas GB, Steyerberg EW, Flach HZ, Marquering HA, Sprengers ME, Jenniskens SF, Beenen LF, van den Berg R, Koudstaal PJ, van Zwam WH, Roos YB, van der Lugt A, van Oostenbrugge RJ, Majoie CB, Dippel DW; MR CLEAN Investigators. A randomized trial of intraarterial treatment for acute ischemic stroke. N Engl J Med. 2015;372:11-20.

29. Nedeltchev K, Brekenfeld C, Remonda L, Ozdoba C, Do DD, Arnold M, Mattle HP, Schroth G. Internal carotid artery stent implantation in 25 patients with acute stroke: preliminary results. Radiology. 2005;237:1029-37.

30. Gratz PP, Schroth G, Gralla J, Mattle HP, Fischer U, Jung S, Mordasini P, Hsieh K, Verma RK, Weisstanner C, El-Koussy M. Whole-brain susceptibility-weighted thrombus imaging in stroke: fragmented thrombi predict worse outcome. AJNR Am J Neuroradiol. 2015. 